University of New Orleans

ScholarWorks@UNO

8-15-1984

\title{
Three-reflection halfwave and quarterwave retarders using dielectric-coated metallic mirrors
}

\author{
T. F. Thonn \\ R. M.A. Azzam \\ University of New Orleans, razzam@uno.edu
}

Follow this and additional works at: https://scholarworks.uno.edu/ee_facpubs

Part of the Electrical and Electronics Commons, and the Optics Commons

\section{Recommended Citation}

T. F. Thonn and R. M. A. Azzam, "Three-reflection halfwave and quarterwave retarders using dielectriccoated metallic mirrors," Appl. Opt. 23, 2752-2759 (1984)

This Article is brought to you for free and open access by the Department of Electrical Engineering at ScholarWorks@UNO. It has been accepted for inclusion in Electrical Engineering Faculty Publications by an authorized administrator of ScholarWorks@UNO. For more information, please contact scholarworks@uno.edu. 


\title{
Three-reflection halfwave and quarterwave retarders using dielectric-coated metallic mirrors
}

\author{
T. F. Thonn and R. M. A. Azzam
}

\begin{abstract}
A design procedure is described to determine the thicknesses of single-layer coatings of a given dielectric on a given metallic substrate so that a specified net phase retardance (and/or a net relative amplitude attenuation) between the $p$ and $s$ polarizations is achieved after three reflections from a symmetrical arrangement of three mirrors that maintain collinearity of the input and output beams. Examples are presented of halfwave and quarterwave retarders (HWR and QWR) that use a $\mathrm{ZnS}-\mathrm{Ag}$ film-substrate system at the $\mathrm{CO}_{2}$ laser wavelength $\lambda=10.6 \mu \mathrm{m}$. The equal net reflectances for the $p$ and $s$ polarizations are computed and found to be high (above $90 \%$ ) for most designs. Sensitivity of the designs (deviation of the magnitude and phase of the ratio of net complex $p$ and $s$ reflection coefficients from design specifications) to small filmthickness and angle-of-incidence errors is examined, and useful operation over a small wavelength range $(10-11 \mu \mathrm{m})$ is demonstrated.
\end{abstract}

\section{Introduction}

An external reflection retarder is a device that introduces a relative phase shift between the parallel $p$ and perpendicular $s$ polarization components of incident monochromatic light without affecting their relative amplitudes. ${ }^{1}$ The design of such single-reflection retarders using optically isotropic film-substrate systems has been amply described and applied..$^{2-7}$ Single-reflection multilayer-coated retarders have also been reported..$^{8-10}$

In this paper we describe the design of three-reflection film-substrate retarders that maintain collinearity of the input and output beams (Fig. 1). In such systems, the individual reflections are not retarding, but the combined net effect of all three reflections produces the desired differential phase shift and equal amplitude attenuation for the $p$ and $s$ polarizations. The method is applied to halfwave and quarterwave retarders (HWR and QWR) that use $\mathrm{ZnS}-\mathrm{Ag}$ (film-substrate) mirrors at the $\mathrm{CO}_{2}$-laser wavelength $\lambda=10.6 \mu \mathrm{m}$. The sensitivity of these designs to small film-thickness and angle-of-incidence errors is examined, and useful operation over a small wavelength range $(10-11 \mu \mathrm{m})$ is demonstrated.

The authors are with University of New Orleans, Department of Electrical Engineering, Lakefront, New Orleans, Louisiana 70148.

Received 16 April 1984.

0003-6935/84/162752-08\$02.00/0.

(C) 1984 Optical Society of America.

\section{Design Procedure}

We consider a symmetrical three-mirror system (Fig. 1 ), where the angles of incidence $\phi_{1}, \phi_{2}$, and $\phi_{3}$ are interrelated as follows:

$$
\begin{aligned}
& \phi_{3}=\phi_{1}, \\
& \phi_{2}=2 \phi_{1}-90^{\circ} .
\end{aligned}
$$

Equation (2) shows that $\phi_{1}$ must be $>45^{\circ}$. We assume an air (or vacuum) ambient of refractive index $N_{0}=1$, a transparent film of refractive index $N_{1}$, and an absorbing metallic substrate of complex refractive index $N_{2}$ for each and all mirrors.

The change of polarization on single reflection from an optically isotropic surface is completely determined by the ratio of complex reflection coefficients,

$$
\rho=R_{p} / R_{s}
$$

of the parallel $p$ and perpendicular $s$ polarizations. For light of wavelength $\lambda$, incident at an angle $\phi$ from a transparent ambient onto a metallic substrate coated by a dielectric film of thickness $d$, the $p$ and $s$ reflection coefficients are given by ${ }^{11}$

$$
R_{\nu}=\frac{r_{01 \nu}+r_{12 \nu} \exp (-j 2 \pi \zeta)}{1+r_{01 \nu} r_{12 \nu} \exp (-j 2 \pi \zeta)}, \nu=p, s .
$$

$r_{01 \nu}$ and $r_{12 \nu}$ are the ambient-film and film-substrate Fresnel's interface reflection coefficients for the $\nu$ polarization, and $\zeta$ is the normalized film thickness:

$$
\zeta=d / D_{\phi}
$$

where

$$
D_{\phi}=\frac{\lambda}{2}\left(N_{1}^{2}-N_{0}^{2} \sin ^{2} \phi\right)^{-1 / 2}
$$




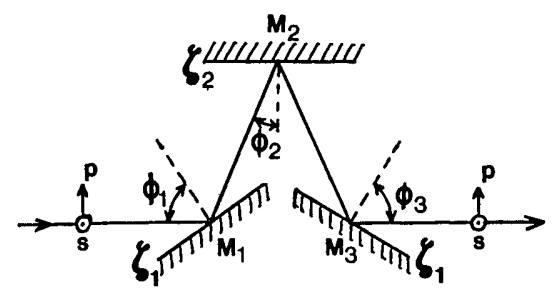

Fig. 1. Three-mirror reflection system.

is the film-thickness period. From Eqs. (3) and (4) we see that $\rho$ is a function of $\phi$ and $\zeta$ :

$$
\rho=f(\phi, \zeta) \text {. }
$$

We require that all mirrors be made of the same metallic substrate coated by a transparent thin film of the same dielectric material and of the same thickness $\zeta_{1}$ for mirrors $M_{1}$ and $M_{3}$ but of a different thickness $\zeta_{2}$ for mirror $M_{2}$. Then we follow a procedure that parallels that described previously by Azzam and Khan. ${ }^{12}$

The net effect of three reflections is given by the product

$$
\rho_{n}=\rho_{1} \rho_{2} \rho_{3}=f^{2}\left(\phi_{1}, \zeta_{1}\right) f\left(\phi_{2}, \zeta_{2}\right)
$$

The ratio of net complex $p$ and $s$ reflection coefficients can be written

$$
\rho_{n}=\left|\rho_{n}\right| \exp \left(j \Delta_{n}\right)
$$

where

$$
\begin{aligned}
\left|\rho_{n}\right| & =\left|R_{p n}\right| /\left|R_{s n}\right|, \\
\Delta_{n} & =\delta_{p n}-\delta_{s n},
\end{aligned}
$$

are the net relative amplitude attenuation and the difference between the net phase shifts experienced by the $p$ and $s$ polarization components, respectively. For a given $\rho_{n}$ the following equation must be solved for $\zeta_{1}, \zeta_{2}$ :

$$
f\left(\phi_{2}, \zeta_{2}\right)=g\left(\phi_{1}, \zeta_{1}\right)
$$

where

$$
g\left(\phi_{1}, \zeta_{1}\right)=\rho_{n} / f^{2}\left(\phi_{1}, \zeta_{1}\right)
$$

Equation (11) can be solved for given $\phi_{1}$ and $\phi_{2}$ using the Newton-Raphson iteration method ${ }^{13}$ on a digital computer. Equation (11) is broken into its real and imaginary parts:

$$
\begin{aligned}
f_{r}\left(\phi_{2}, \zeta_{2}\right) & =g_{r}\left(\phi_{1}, \zeta_{1}\right), \\
f_{i}\left(\phi_{2}, \zeta_{2}\right) & =g_{i}\left(\phi_{1}, \zeta_{1}\right),
\end{aligned}
$$

where

$$
f=f_{r}+j f_{i}, \quad g=g_{r}+j g_{i} .
$$

We look for solutions $\zeta_{1}, \zeta_{2}$ of Eqs. (13) in the reduced thickness range:

$$
0 \leq \zeta_{1,2}<1 .
$$

An arbitrary initial trial solution $\left(\zeta_{1}^{0}, \zeta_{2}^{0}\right)$ is assumed that will be incremented by $\left(\Delta \zeta_{1}, \Delta \zeta_{2}\right)$ to move closer to the correct solution. The new vector $\left(\zeta_{1}^{0}+\Delta \zeta_{1}, \zeta_{2}^{0}+\Delta \zeta_{2}\right)$ is then required to satisfy Eqs. (13):

$$
\begin{aligned}
& f_{r}\left(\phi_{2}, \zeta_{2}^{0}+\Delta \zeta_{2}\right)=g_{r}\left(\phi_{1}, \zeta_{1}^{0}+\Delta \zeta_{1}\right), \\
& f_{i}\left(\phi_{2}, \zeta_{2}^{0}+\Delta \zeta_{2}\right)=g_{i}\left(\phi_{1}, \zeta_{1}^{0}+\Delta \zeta_{1}\right) .
\end{aligned}
$$

The initial vector is assumed to be sufficiently close to the correct solution to justify a linear two-term Taylor-series expansion of Eqs. (16); this gives

$$
\begin{aligned}
& f_{r}^{\prime}\left(\phi_{2}, \zeta_{2}^{0}\right) \Delta \zeta_{2}-g_{r}^{\prime}\left(\phi_{1}, \zeta_{1}^{0}\right) \Delta \zeta_{1}=g_{r}\left(\phi_{1}, \zeta_{1}^{0}\right)-f_{r}\left(\phi_{2}, \zeta_{2}^{0}\right), \\
& f_{i}^{\prime}\left(\phi_{2}, \zeta_{2}^{0}\right) \Delta \zeta_{2}-g_{i}^{\prime}\left(\phi_{1}, \zeta_{1}^{0}\right) \Delta \zeta_{1}=g_{i}\left(\phi_{1}, \zeta_{1}^{0}\right)-f_{i}\left(\phi_{2}, \zeta_{2}^{0}\right) .
\end{aligned}
$$

In Eqs. (17) the prime superscript indicates the first partial derivative with respect to $\zeta$ (i.e., $f_{r}=\partial f_{r} / \partial \zeta$ etc). These derivatives are obtained from Eqs. (3) and (4) as follows:

$$
\begin{aligned}
f^{\prime} & =\rho^{\prime}=\left(R_{p}^{\prime} / R_{s}\right)-\left(R_{p} R_{s}^{\prime} / R_{s}^{2}\right), \\
R_{\nu}^{\prime} & =-j 2 \pi \exp (-j 2 \pi \zeta) \frac{r_{12 \nu}\left(1-r_{01 \nu}^{2}\right)}{\left[1+r_{01 \nu} r_{12 \nu} \exp (-j 2 \pi \zeta)\right]^{2}}, \nu=p, s, \\
g^{\prime} & =-2 \rho_{n} f^{\prime} / f^{3}, \\
f_{r}^{\prime} & =\operatorname{Re} f^{\prime}, f_{i}^{\prime}=\operatorname{Im} f^{\prime} ; g_{r}^{\prime}=\operatorname{Reg}^{\prime}, g_{i}^{\prime}=\operatorname{Im} g^{\prime} .
\end{aligned}
$$

The two linear algebraic equations (17) are solved for $\Delta \zeta_{1}, \Delta \zeta_{2}$. The new vector $\left(\zeta_{1}^{0}+\Delta \zeta_{1}, \zeta_{2}^{0}+\Delta \zeta_{2}\right)$ is determined and used as the improved initial vector for the next round of iteration. This process is repeated until the changes of $\Delta \zeta_{1}, \Delta \zeta_{2}$ between iteration steps both fall below $10^{-6}$, at which point the solution is considered reached. As a check, the final solution vector $\left(\zeta_{1}, \zeta_{2}\right)$ is substituted into the right-hand side of Eq. (8), and $\rho_{n}$ is verified to be the desired $\rho_{n}$.

The design procedure is general and can be applied at any wavelength to any film-substrate system and for any desired net ratio of complex reflection coefficients $\rho_{n}$. However, for any given combination of parameters and angle of incidence $\phi_{1}$, no solution, one solution, or multiple solutions may exist. Thus it was necessary to plot, in the complex plane, the closed contours of $\rho_{2}$ and $\rho_{n} / \rho_{1}^{2}$ at given $\phi_{1}$ (as $\zeta_{1}$ and $\zeta_{2}$ vary from 0 to 1 ) to verify the number of solutions (points of intersection) before doing the actual iteration.

We have found the above-described Newton-Raphson method to be adequate and that it converges after a reasonable number of iterations (usually $<40$ ), when an initial vector sufficiently close to the solution vector is chosen. All multiple solutions could be found by beginning iteration from different initial vectors.

Note that if $\left(\zeta_{1}, \zeta_{2}\right)$ is a solution, $\left(\zeta_{1}+m, \zeta_{2}+n\right)$ will also be a solution, where $m$ and $n$ are any two positive integers. This follows from the fact that $R_{p}, R_{s}$, and $\rho$ are periodic functions of $\zeta$ with period 1 , as can be seen from Eqs. (3) and (4). The actual thicknesses of the film on mirrors $M_{1}, M_{3}$, and $M_{2}$ are then given by

$$
\left(d_{1}, d_{2}\right)=\left(\zeta_{1} D_{\phi 1}, \zeta_{2} D_{\phi 2}\right)
$$

The net intensity reflectances of the three-mirror system can be calculated from Eq. (4) as

$$
\mathcal{R}_{\nu n}=\left|R_{\nu 1}\right|^{2}\left|R_{\nu 2}\right|^{2}\left|R_{\nu 3}\right|^{2}, \quad \nu=p \text { or } s,
$$

where $R_{\nu i}$ is the reflection coefficient for the $\nu$ polarization of mirror $M_{i}$ (note that $R_{\nu 1}=R_{\nu 3}$ by design). In 


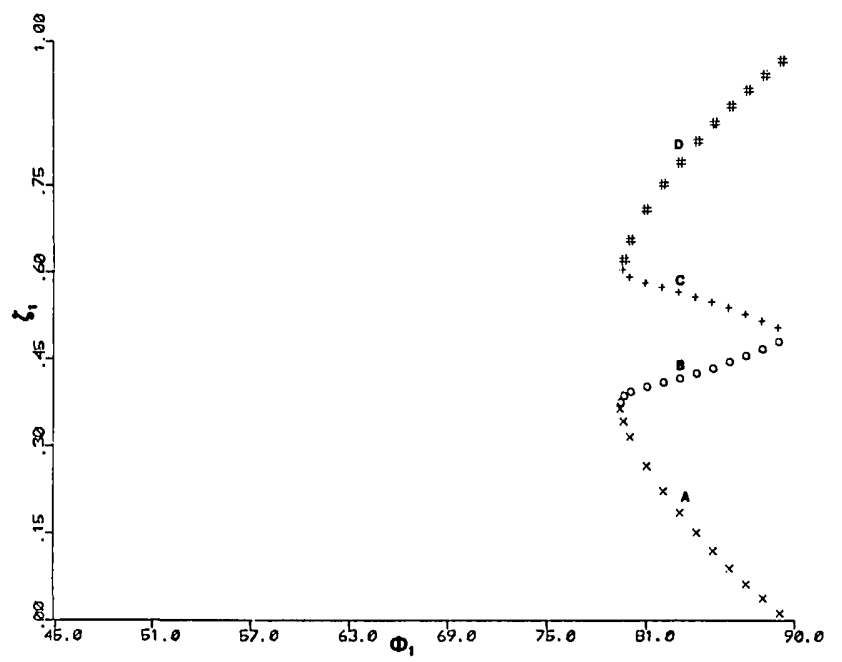

- Fig. 2. Normalized film thickness $\zeta_{1}$ required for $\operatorname{HWR}\left(\left|\rho_{n}\right|=1\right.$, $\Delta_{n}= \pm 180^{\circ}$ ) vs angle of incidence $\phi_{1}(\mathrm{deg})$ in a $\mathrm{ZnS}-\mathrm{Ag}$ three-reflection system at $\lambda=10.6 \mu \mathrm{m}$.

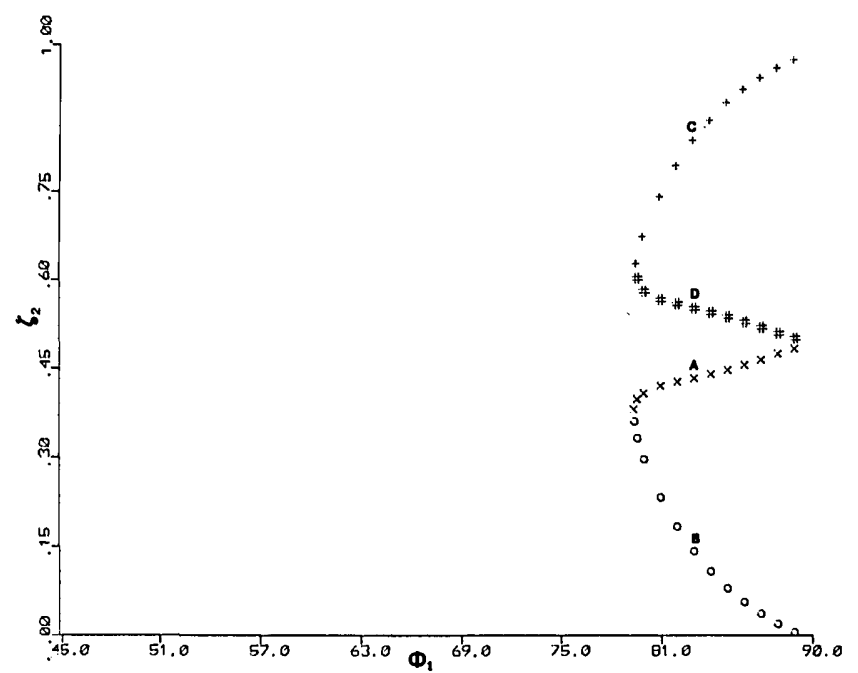

Fig. 3. Same as in Fig. 2 for the associated normalized film thickness $\zeta_{2}$. this paper, we consider only pure retarders, i.e., $\left|\rho_{n}\right|=$ 1 and

$$
\mathcal{R}_{p n}=\mathcal{R}_{\text {sn }} \text {. }
$$

High values of $\mathcal{R}_{\nu n}$ are achieved when the substrate is metallic.

In the following examples, we will also examine the sensitivity of a design to small film-thickness and angle-of-incidence errors and to small wavelength changes. This is done by direct calculation of $\rho_{n}$ from Eq. (8) with the design parameters perturbed by the corresponding error, namely, $\Delta d_{1}=\Delta d_{2}\left(\Delta \xi_{i}=\Delta d_{i}\right.$ $\left./ D_{\phi i}\right), \Delta \phi_{1}=\Delta \phi_{2}$, or $\Delta \lambda$. The deviation from the desired $\rho_{n}$ is expressed in terms of separate magnitude and phase errors:

$$
\begin{gathered}
\text { magnitude error }=\left|\rho_{n}\right|-1, \\
\text { phase error }=\Delta_{n}-\Delta_{n d},
\end{gathered}
$$

where $\Delta_{n d}$ is the desired retardance. Wavelength sensitivity is computed neglecting the effect of material dispersion over the test range. Thus the wavelength shift $\Delta \lambda$ has the same effect as simultaneous filmthickness errors $\Delta d_{i}$ so that $\Delta d_{i} / d_{i}=\Delta \lambda / \lambda$ and $i=1,2,3$ for the respective mirror.

\section{ZnS-Ag Halfwave Retarders at $\lambda=10.6 \mu \mathrm{m}$}

As a first example, we have designed three-reflection halfwave retarders at the $\mathrm{CO}_{2}$-laser wavelength $\lambda=10.6$ $\mu \mathrm{m}$ using mirrors that consist of a transparent film of $\mathrm{ZnS}\left(N_{1}=2.2\right)$ on a Ag substrate $\left(N_{2}=9.5-j 73\right)^{8}$ in an air ambient $\left(N_{0}=1\right)$.

The design procedure of Sec. II was applied with $\left|\rho_{n}\right|$ $=1$ and $\Delta_{n}= \pm 180^{\circ}$ (HWR) at discrete angles of incidence $\phi_{1}$ over the full range $45^{\circ}<\phi_{1}<90^{\circ}$. Figures 2 and 3 give the solutions for the normalized film thicknesses $\zeta_{1}$ and $\zeta_{2}$ plotted vs $\phi_{1}$.

Table I lists a summary of the HWR design results for two angles of incidence: 80 and $85^{\circ}$. The table gives the normalized film-thickness solution pairs $\left(\zeta_{1}, \zeta_{2}\right)$, film-thickness periods $D_{\phi 1}$ and $D_{\phi 2}$, the net reflectance $\mathcal{R}_{\nu n}(\nu=p, s)$, and the net phase shifts $\delta_{p n}$ and $\delta_{s n}$ experienced by the $p$ and $s$ components of polarization, respectively. From Figs. 2 and 3 we see that solutions exist only in the limited range $79.4^{\circ} \leq \phi_{1}<90^{\circ}$. Within

Table I. Summary of Design Results for ZnS-Ag Three-Reflection Halfwave Retarders (HWR: $\left|\rho_{n}\right|=1, \Delta_{n}$ $=\delta_{p n}-\delta_{s n}= \pm 180^{\circ}$ ) at Two Angles of Incidence and for Wavelength $\lambda=10.6 \mu \mathrm{m}$

\begin{tabular}{rcccccrr}
\hline$\phi_{1}$ & $\zeta_{1}$ & $\zeta_{2}$ & $D_{\phi 1}$ & $D_{\phi 2}$ & $\mathcal{R}_{\nu n}$ & \multicolumn{1}{c}{$\delta_{p n}$} & $\delta_{s n}$ \\
\hline $80 A$ & 0.31634 & 0.40638 & 2.6941 & 2.6644 & 0.9672 & -96.965 & 83.035 \\
$B$ & 0.39404 & 0.29610 & 2.6941 & 2.6644 & 0.9689 & -89.782 & 90.218 \\
$C$ & 0.59110 & 0.67256 & 2.6941 & 2.6644 & 0.9689 & 91.178 & -88.822 \\
$D$ & 0.65557 & 0.58024 & 2.6941 & 2.6644 & 0.9675 & 97.402 & -82.598 \\
$85 A$ & 0.11938 & 0.44629 & 2.7020 & 2.6941 & 0.9557 & -67.599 & 112.401 \\
$B$ & 0.43494 & 0.07680 & 2.7020 & 2.6941 & 0.9627 & -58.252 & 121.748 \\
$C$ & 0.54840 & 0.90090 & 2.7020 & 2.6941 & 0.9629 & 58.296 & -121.704 \\
$D$ & 0.85867 & 0.53708 & 2.7020 & 2.6941 & 0.9560 & 67.523 & -112.477 \\
\hline
\end{tabular}

${ }^{a} \phi_{1}$ is the angle of incidence in degrees on mirrors $M_{1}$ and $M_{3} ;\left(\zeta_{1}, \zeta_{2}\right)$ is the normalized film-thickness solution pair; $D_{\phi i}$ is the film-thickness period in microns at $\phi_{i}, i=1,2 ; \mathcal{R}_{\nu n}$ is the net reflectance of the retarder for both polarizations $(\nu=p, s)$; and $\delta_{p n}, \delta_{s n}$ are the net phase shifts for the $p$ and $s$ polarizations in degrees. The refractive indices of $\mathrm{ZnS}$ and $\mathrm{AG}$ at $10.6 \mu \mathrm{m}$ are taken to be 2.2 and $9.5-j 73$, respectively. 


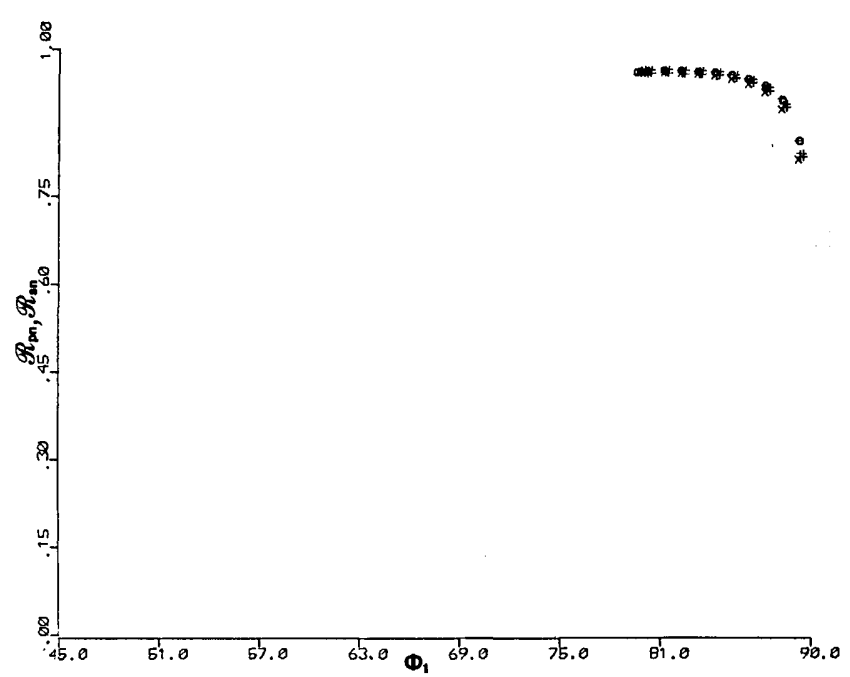

Fig. 4. Net intensity reflectances $\mathcal{R}_{p n}=\mathscr{R}_{s n}$ associated with the design solution pairs $\left(\zeta_{1}, \zeta_{2}\right)$ of Figs. 2 and 3.

Table II. Magnitude and Phase Errors Caused by Introducing (I) FilmThickness Errors $\left(\Delta d_{1}=\Delta d_{2}= \pm 1 \mathrm{~nm}\right)$, (II) Angle-of-Incidence Errors $\left(\Delta \phi_{1}=\Delta \phi_{2}=\Delta \phi_{3}= \pm 0.5^{\circ}\right)$ to the HWR Designs of Table I

\begin{tabular}{|c|c|c|c|c|c|}
\hline \multirow{2}{*}{$\begin{array}{c}\text { Error } \\
\text { type }\end{array}$} & \multirow[b]{2}{*}{$\phi_{1}(\mathrm{deg})$} & \multicolumn{2}{|c|}{$\begin{array}{l}\text { Magnitude error } \\
\left(\left|\rho_{n}\right|-1\right) \times 10^{4}\end{array}$} & \multicolumn{2}{|c|}{$\begin{array}{c}\text { Phase error } \\
\left(\Delta_{n} \mp 180^{\circ}\right)(\mathrm{deg})\end{array}$} \\
\hline & & - & + & - & + \\
\hline \multirow[t]{8}{*}{ I } & $80 \mathrm{~A}$ & -1.010 & 1.018 & -0.0613 & 0.0633 \\
\hline & $B$ & -1.017 & 1.027 & -0.0577 & 0.0597 \\
\hline & $C$ & 1.007 & -0.999 & -0.0597 & 0.0578 \\
\hline & $D$ & 0.990 & -0.985 & -0.0626 & 0.0607 \\
\hline & $85 \bar{A}$ & -3.345 & 3.380 & -0.0865 & 0.0927 \\
\hline & $B$ & -2.536 & 2.586 & -0.0714 & 0.0766 \\
\hline & $C$ & 2.567 & -2.525 & -0.0761 & 0.0713 \\
\hline & $D$ & 3.346 & -3.310 & -0.0921 & 0.0859 \\
\hline \multirow[t]{8}{*}{ II } & $80 \mathrm{~A}$ & -2.061 & 2.088 & 6.0568 & -6.1141 \\
\hline & $B$ & 1.385 & -1.430 & 6.1212 & -6.1799 \\
\hline & C & 1.188 & -1.230 & -6.1639 & 6.2222 \\
\hline & $D$ & -1.777 & 1.797 & -6.0734 & 6.1299 \\
\hline & $85 \mathrm{~A}$ & -6.922 & 8.039 & 12.1470 & -12.5933 \\
\hline & $B$ & 15.510 & -15.953 & 8.7586 & -9.0116 \\
\hline & $C$ & 15.306 & -15.745 & -8.8312 & 9.0848 \\
\hline & $D$ & -6.934 & 8.030 & -12.1470 & 12.5889 \\
\hline
\end{tabular}

this range we see four distinct solution pairs (branches $A, B, C, D)$ that achieve HWR for each $\phi_{1}$.

Figures 2 and 3 are nearly symmetrical with respect to the line $\zeta_{1,2}=0.5$ due to the near symmetry of the constant-angle-of-incidence contours (CAIC) in the complex $\rho$ plane with respect to the real axis. ${ }^{2}$ Table I also indicates that for each thickness-solution pair that gives a net relative phase shift $\Delta_{n}=180^{\circ}$ there exists a corresponding solution that gives the equivalent retardance $\Delta_{n}=-180^{\circ}$, so that $\zeta_{A}+\zeta_{D} \simeq 1, \zeta_{B}+\zeta_{C}$ $\simeq 1$ (because the $\zeta=0$ point on the CAIC is almost on the real axis).

Figure 4 gives a plot of the net intensity reflectance $\mathscr{R}_{\nu n}$ for both polarizations vs $\phi_{1}$ for the solution pairs of Figs. 2 and 3. From Fig. 4 and Table I we see that $\mathscr{R}_{\nu n}$ is nearly the same for all solutions at a specific $\phi_{1}$. $\mathcal{R}_{\nu n}$ decreases as $\phi_{1}$ increases, first slowly then rapidly near $\phi_{1}=90^{\circ}$, but remains high ( $\left.>90 \%\right)$ for all angles of incidence $\leq 88^{\circ}$.

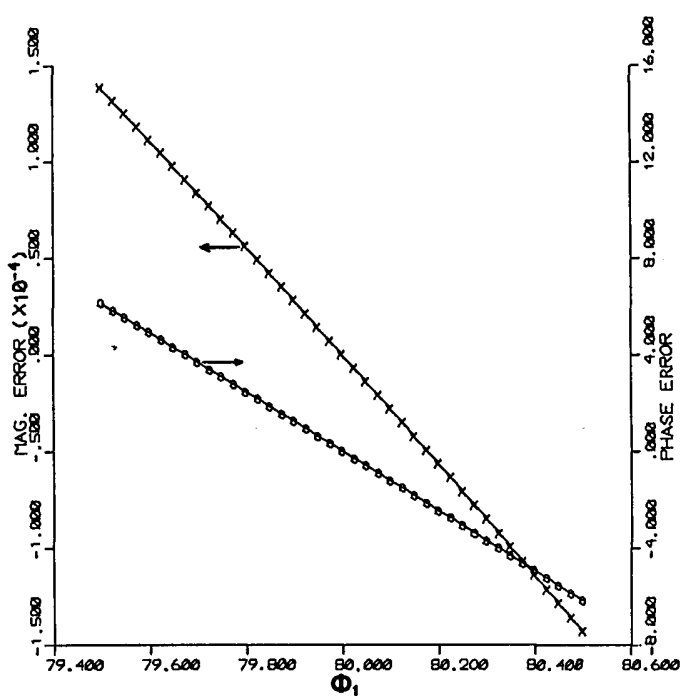

Fig. 5. Magnitude error $\left(\left|\rho_{n}\right|-1\right)$ and phase error $\left[\Delta_{n}-\left(180^{\circ}\right)\right]$ caused by angle-of-incidence $\Delta \phi_{1}=\Delta \phi_{2}=\Delta \phi_{3}= \pm 0.5^{\circ}$ for solution pair $B$ at $\phi_{1}=80^{\circ}$ of Table I.

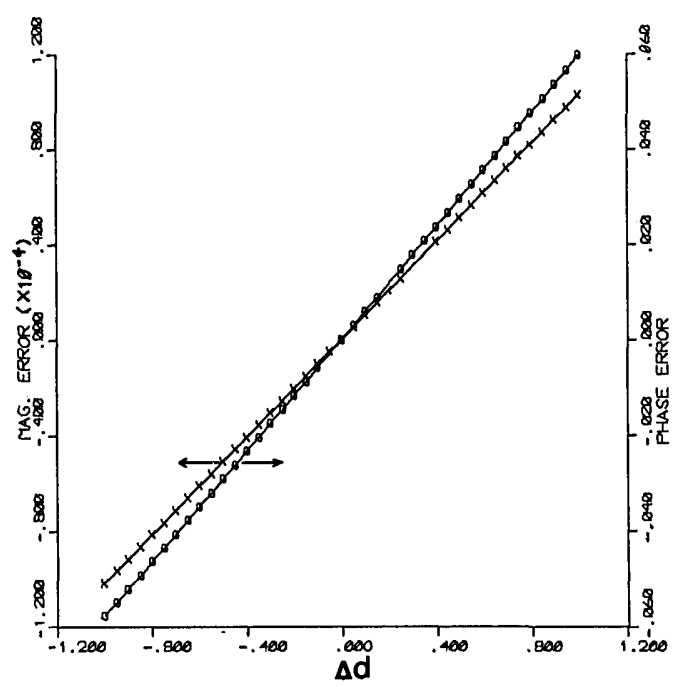

Fig. 6. Same as in Fig. 5 for $\Delta d_{1}=\Delta d_{2}= \pm 1$-nm changes of actual film thickness $d_{1}$ and $d_{2}$.

Table II gives the magnitude and phase errors generated by thickness errors $\Delta d_{1}=\Delta d_{2}= \pm 1 \mathrm{~nm}$ and angle-of-incidence errors $\Delta \phi_{1}=\Delta \phi_{2}=\Delta \phi_{3}= \pm 0.5^{\circ}$. The errors at $85^{\circ}$ are higher than those for the $80^{\circ} \mathrm{de}$ signs.

Figures 5 and 6 show that these magnitude and phase errors vary essentially linearly with $\Delta \phi_{i}$ between $\pm 0.5^{\circ}$ and with $\Delta d_{i}$ between $\pm 1 \mathrm{~nm}$ for a specific design (solution $B$ at $\phi_{1}=80^{\circ}$ ).

Figure 7 shows the magnitude and phase errors that result when the wavelength $\lambda$ scans the range $10 \mu \mathrm{m} \leq$ $\lambda \leq 11 \mu \mathrm{m}$ about the design wavelength $\lambda=10.6 \mu \mathrm{m}$ for the same solution $B$ at $\phi_{1}=80^{\circ}$, neglecting the effect of material dispersion. Over this $1-\mu \mathrm{m}$ wide spectral band, the system operates satisfactorily as a HWR with the magnitude error $<1 \%$ and phase error $<5 \%$. 


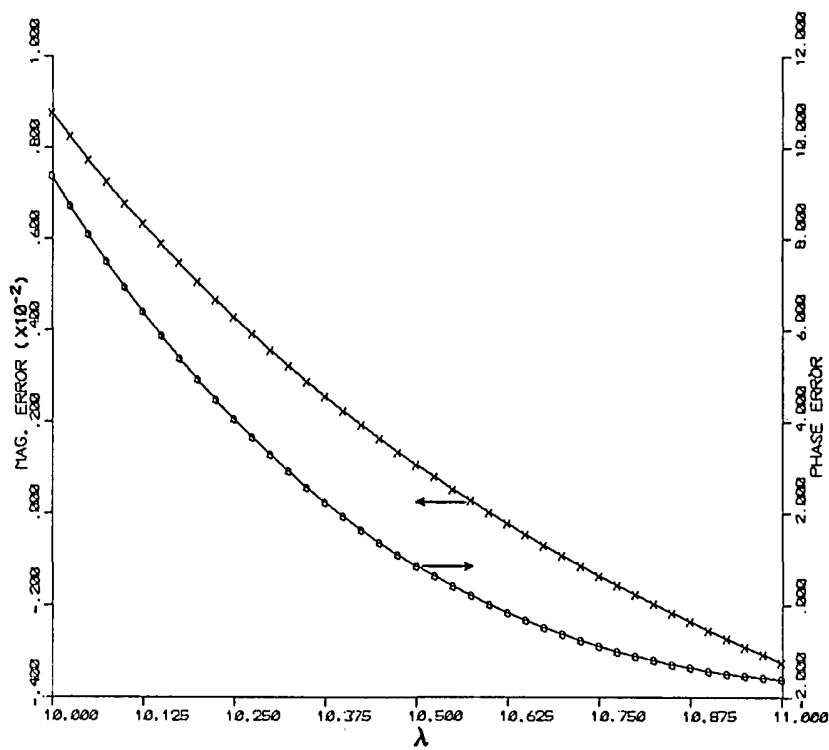

Fig. 7. Same as in Fig. 5 for wavelength changes in the range $10 \mu \mathrm{m}$ $\leq \lambda \leq 11 \mu \mathrm{m}$.

\section{ZnS-Ag Quarterwave Retarders at $\lambda=10.6 \mu \mathrm{m}$}

\section{A. $\rho_{n}=+j$ Quarterwave Retarders ( $p$ Fast Axis)}

We again assume mirrors that consist of a $\mathrm{ZnS}$ film on an Ag substrate at $10.6 \mu \mathrm{m}$ with the same optical constants given in Sec. III.

The design procedure of Sec. II was applied with $\left|\rho_{n}\right|$ $=1$ and $\Delta_{n}=90^{\circ}(\mathrm{QWR})$ at discrete angles $\phi_{1}$ in the range $45^{\circ}<\phi_{1}<90^{\circ}$. Figures 8 and 9 give the solutions for $\zeta_{1}$ and $\zeta_{2}$ plotted vs $\phi_{1}$. Table III summarizes QWR design results for three angles of incidence: 52,75 , and $85^{\circ}$. From Figs 8 and 9 we see that multiple solutions at a specific $\phi_{1}$ exist as follows. Two solutions are available in the ranges $51^{\circ} \leq \phi_{1} \leq 52^{\circ}$ and $73.2^{\circ} \leq \phi_{1}$ $\leq 79^{\circ}$, four in the range $80^{\circ} \leq \phi_{1} \leq 84^{\circ}$, and six solutions in the range $85^{\circ} \leq \phi_{1}<90^{\circ}$.

In Fig. 10 the net intensity reflectance $\mathscr{R}_{\nu n}$ is plotted vs $\phi_{1}$ for the solutions of Figs. 8 and 9 . $\mathcal{R}_{\nu n}$ is high for most solutions except near grazing incidence $\left(\phi_{1}=90^{\circ}\right)$ where it falls off rapidly.

Table IV shows the magnitude and phase errors caused by $\Delta d_{i}= \pm 1$-nm thickness errors and $\Delta \phi_{i}=$

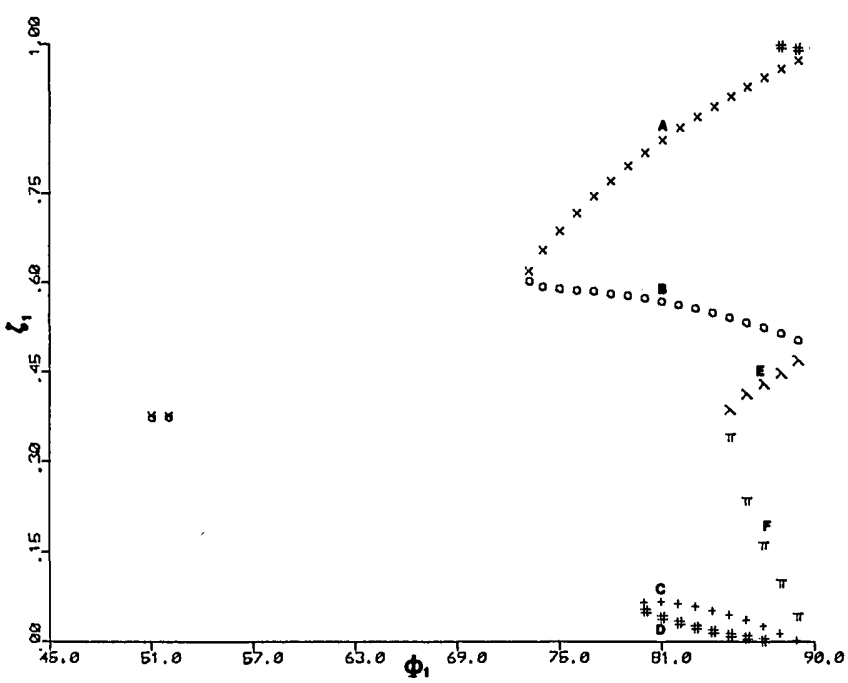

Fig. 8. Normalized film thickness $\zeta_{1}$ required for QWR $\left(\left|\rho_{n}\right|=1\right.$, $\Delta_{n}=90^{\circ}$ ) vs angle of incidence $\phi_{1}(\mathrm{deg})$ in a $\mathrm{ZnS}-\mathrm{Ag}$ three-reflection system at $\lambda=10.6 \mu \mathrm{m}$.

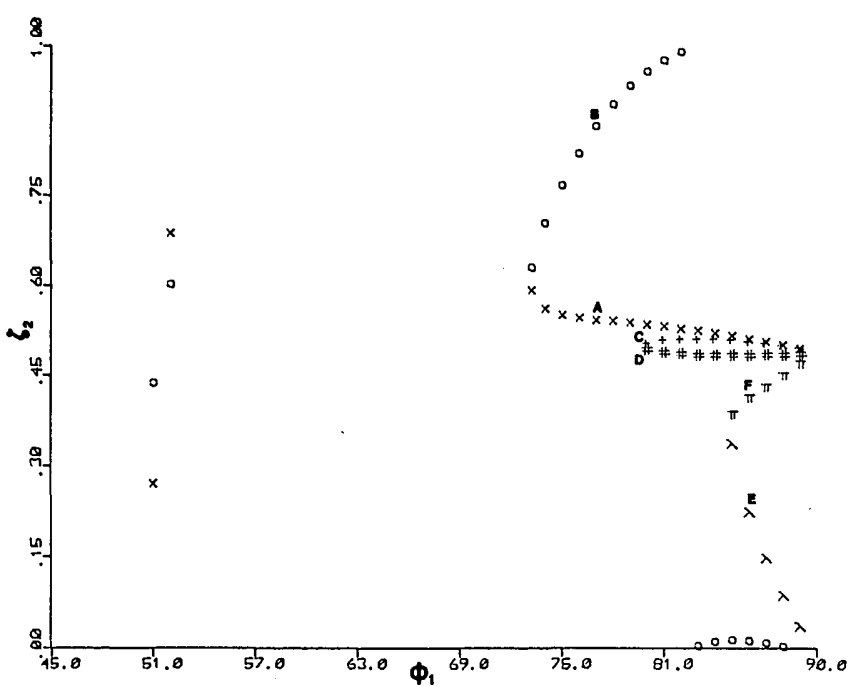

Fig. 9. Same as in Fig. 2 for the associated normalized film thickness $\zeta_{2}$.

Table III. Summary of Design Results for ZnS-Ag Three-Reflectlon Quarterwave Retarders with $p$ Fast Axls (QWR: $\left|\rho_{n}\right|=1, \Delta_{n}=\delta_{p n}-\delta_{s n}=90^{\circ}$ ) at Three Angles of Incidence and for Wavelength $\lambda=10.6 \mu \mathrm{m} *$

\begin{tabular}{rcccccrr}
\hline$\phi_{1}$ & $\zeta_{1}$ & $\zeta_{2}$ & $D_{\phi 1}$ & $D_{\phi 2}$ & $\mathcal{R}_{\nu n}$ & \multicolumn{1}{c}{$\delta_{p n}$} & \multicolumn{1}{c}{$\delta_{s n}$} \\
\hline $52 A$ & 0.37716 & 0.68985 & 2.5751 & 2.4238 & 0.9445 & 178.381 & 88.381 \\
$B$ & 0.37578 & 0.60396 & 2.5751 & 2.4238 & 0.9368 & -143.182 & 126.818 \\
$75 A$ & 0.68770 & 0.55294 & 2.6814 & 2.6207 & 0.9541 & 55.070 & -34.930 \\
$B$ & 0.59026 & 0.77066 & 2.6814 & 2.6207 & 0.9617 & 22.095 & -67.905 \\
$85 A$ & 0.91588 & 0.51795 & 2.7020 & 2.6941 & 0.9188 & 5.903 & -84.097 \\
$B$ & 0.54189 & 0.01364 & 2.7020 & 2.6941 & 0.9541 & -28.401 & -118.401 \\
$C$ & 0.04588 & 0.51154 & 2.7020 & 2.6941 & 0.9001 & 17.318 & -72.682 \\
$D$ & 0.01175 & 0.48696 & 2.7020 & 2.6941 & 0.8578 & 108.005 & 18.005 \\
$E$ & 0.38691 & 0.33921 & 2.7020 & 2.6941 & 0.9831 & -138.976 & 131.024 \\
$F$ & 0.34169 & 0.38882 & 2.7020 & 2.6941 & 0.9830 & -139.512 & 130.488 \\
\hline
\end{tabular}

a See footnote of Table I for explanation of notation. 


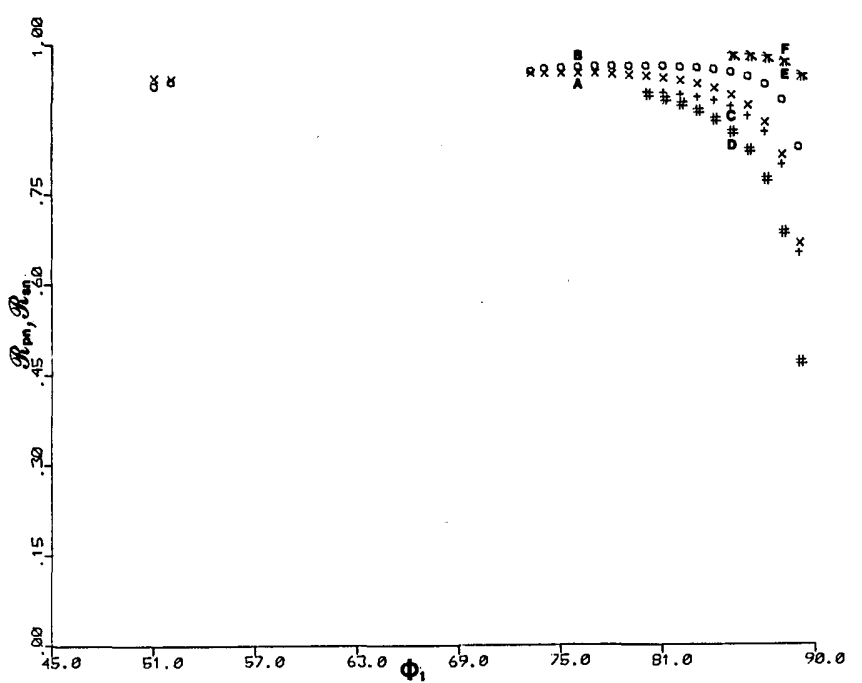

Fig. 10. Net intensity reflectances $\mathcal{R}_{p n}=\mathcal{R}_{s n}$ associated with the design solution pairs $\left(\zeta_{1}, \zeta_{2}\right)$ of Figs. 8 and 9.

Table IV. Magnitude and Phase Errors Caused by Introducing (I) FilmThickness Errors ( $\Delta d_{1}=\Delta d_{2}= \pm 1 \mathrm{~nm}$ ), (II) Angle-of-Incidence Errors $\left(\Delta \phi_{1}=\Delta \phi_{2}=\Delta \phi_{3}= \pm 0.5^{\circ}\right)$ to the QWR Designs of Table III

\begin{tabular}{|c|c|c|c|c|c|}
\hline \multirow{2}{*}{$\begin{array}{l}\text { Error } \\
\text { type }\end{array}$} & \multirow[b]{2}{*}{$\phi_{1}(\mathrm{deg})$} & \multicolumn{2}{|c|}{$\begin{array}{l}\text { Magnitude error } \\
\left(\left|\rho_{n}\right|-1\right) \times 10^{4}\end{array}$} & \multicolumn{2}{|c|}{$\begin{array}{c}\text { Phase Error } \\
\left(\Delta_{n}-90^{\circ}\right)(\mathrm{deg})\end{array}$} \\
\hline & & - & + & - & + \\
\hline \multirow[t]{10}{*}{ I } & $52 A$ & -0.603 & 0.608 & -0.0537 & 0.0550 \\
\hline & $B$ & -0.573 & 0.576 & -0.0546 & 0.0557 \\
\hline & $75 A$ & 1.072 & -1.067 & -0.0817 & 0.0797 \\
\hline & B & 1.101 & -1.092 & -0.0682 & 0.0660 \\
\hline & $85 \mathrm{~A}$ & 7.479 & -7.417 & -0.1746 & 0.1609 \\
\hline & $B$ & 2.988 & -2.916 & -0.0943 & 0.0884 \\
\hline & $C$ & 3.982 & -3.949 & -0.2133 & 0.2046 \\
\hline & $D$ & -5.518 & 5.314 & -0.3010 & 0.3106 \\
\hline & $E$ & -0.575 & 0.579 & -0.0330 & 0.0341 \\
\hline & $F$ & -0.571 & 0.575 & -0.0333 & 0.0344 \\
\hline \multirow[t]{10}{*}{ II } & $52 A$ & -0.093 & 0.09 & 1.9350 & -1.9622 \\
\hline & $B$ & -0.206 & 0.213 & 1.9246 & -1.9512 \\
\hline & $75 \mathrm{~A}$ & -2.734 & 2.850 & -5.1858 & 5.2592 \\
\hline & $B$ & 1.402 & -1.483 & -5.0627 & 5.1303 \\
\hline & $85 A$ & -4.169 & 7.389 & -14.0402 & 15.2408 \\
\hline & B & 24.356 & -26.014 & -5.7013 & 5.7001 \\
\hline & $C$ & 0.813 & 2.351 & 8.0346 & -9.1883 \\
\hline & $D$ & 20.245 & -25.010 & 7.1403 & -8.4625 \\
\hline & $E$ & 0.842 & -0.858 & 6.6376 & -6.6682 \\
\hline & $F$ & -1.007 & 1.000 & 6.5501 & -6.5804 \\
\hline
\end{tabular}

$\pm 0.5^{\circ}$ angle-of-incidence errors. Again we see a general increase in these errors with $\phi_{1}$. Although not shown here, we have also verified that for these designs the magnitude and phase errors vary essentially linearly with $\Delta d_{i}$ between $\pm 1 \mathrm{~nm}$ and with $\Delta \phi_{i}$ between $\pm 0.5^{\circ}$, as expected.

Figure 11 shows the magnitude and phase errors that result when the wavelength $\lambda$ scans the range $10 \mu \mathrm{m} \leq$ $\lambda \leq 11 \mu \mathrm{m}$ for solution $B$ at $\phi_{1}=75^{\circ}$. Again the effect of material dispersion is neglected. The magnitude error remains $<1 \%$ and the phase error $<8 \%$, indicating acceptable performance as a QWR over this spectral range.

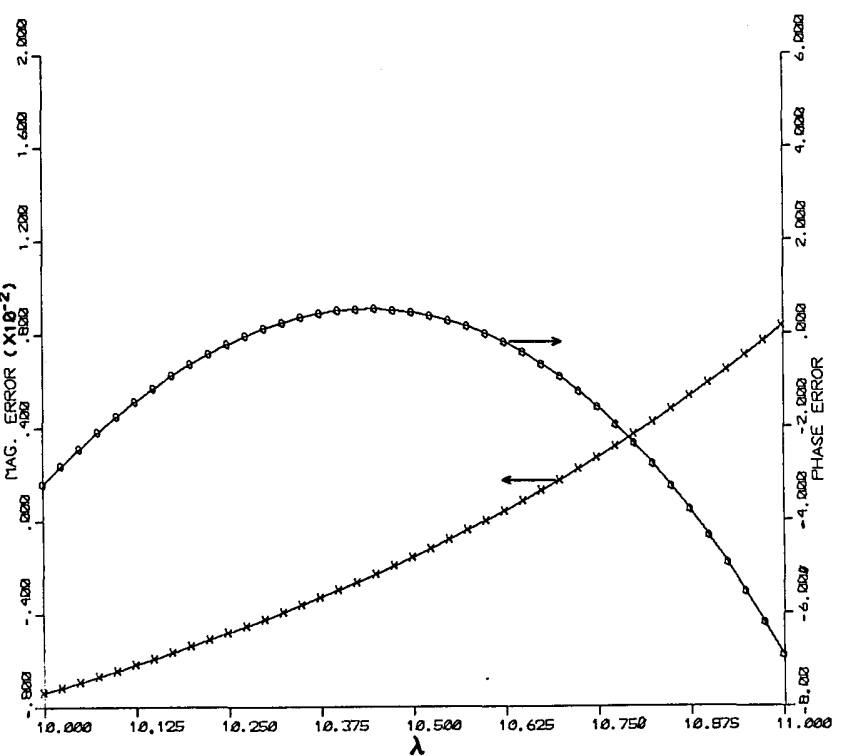

Fig. 11. Magnitude error $\left(\left|\rho_{n}\right|-1\right)$ and phase error $\left(\Delta_{n}-90^{\circ}\right)$ caused by wavelength changes in the range $10 \mu \mathrm{m} \leq \lambda \leq 11 \mu \mathrm{m}$ for solution pair $B$ at $\phi_{1}=75^{\circ}$ of Table III.

\section{B. $\rho_{n}=-j$ Quarterwave Retarders ( $s$ Fast Axis)}

The ZnS-Ag film-substrate system is assumed with optical constants at $10.6 \mu \mathrm{m}$ given in Sec. III, as before.

The design procedure of Sec. II was applied with $\left|\rho_{n}\right|$ $=1$ and $\Delta_{n}=-90^{\circ}(\mathrm{QWR})$ at discrete angles $\phi_{1}$ in the range $45^{\circ}<\phi_{1}<90^{\circ}$. Figures 12 and 13 show the solutions $\zeta_{1}$ and $\zeta_{2}$ plotted vs $\phi_{1}$. Table V summarizes QWR design results for the three angles of incidence 52, 75 , and $85^{\circ}$. From Figs. 12 and 13 we see that multiple solutions of the same number at a specific $\phi_{1}$ exist in the same ranges as those found for the $\Delta_{n}=90^{\circ} \mathrm{QWR}$. A near-inverse relation exists between the solution branches of these figures and the corresponding ones in Figs. 8 and 9, i.e., $\zeta_{1 A}\left(+90^{\circ}\right)+\zeta_{1 A}\left(-90^{\circ}\right) \simeq 1$ etc., again due to the symmetry of the CAIC as discussed in Sec. III. "For each thickness solution that leads to a net relative phase shift $\Delta_{n}=90^{\circ}$, there exists a corresponding solution that makes $\Delta_{n}=-90^{\circ}$.

Figure 14 gives a plot of $\mathcal{R}_{\nu n}$ vs $\phi_{1}$ for the solution pairs of Figs. 12 and 13. This is nearly an exact copy of Fig. 10, as is also seen by comparing the corresponding entries of $\mathcal{R}_{\nu n}$ in Tables III and V.

Table VI shows the magnitude and phase errors caused by $\Delta d_{i}= \pm 1$-nm thickness errors and $\Delta \phi_{i}=$ $\pm 0.5^{\circ}$ angle-of-incidence errors. These errors are nearly the same as the corresponding errors shown in Table IV. Again we see a general increase in these errors with $\phi_{1}$. And these errors also vary essentially linearly with $\Delta d_{i}$ between $\pm 1 \mathrm{~nm}$ and with $\Delta \phi_{i}$ between $\pm 0.5^{\circ}$.

Figure 15 shows the magnitude and phase errors that result when the wavelength $\lambda$ varies in the range $10 \mu \mathrm{m}$ $\leq \lambda \leq 11 \mu \mathrm{m}$ for solution $A$ at $\phi_{1}=75^{\circ}$, with material dispersion again neglected. The phase error stays below $15 \%$, and the magnitude error is $<1 \%$. 


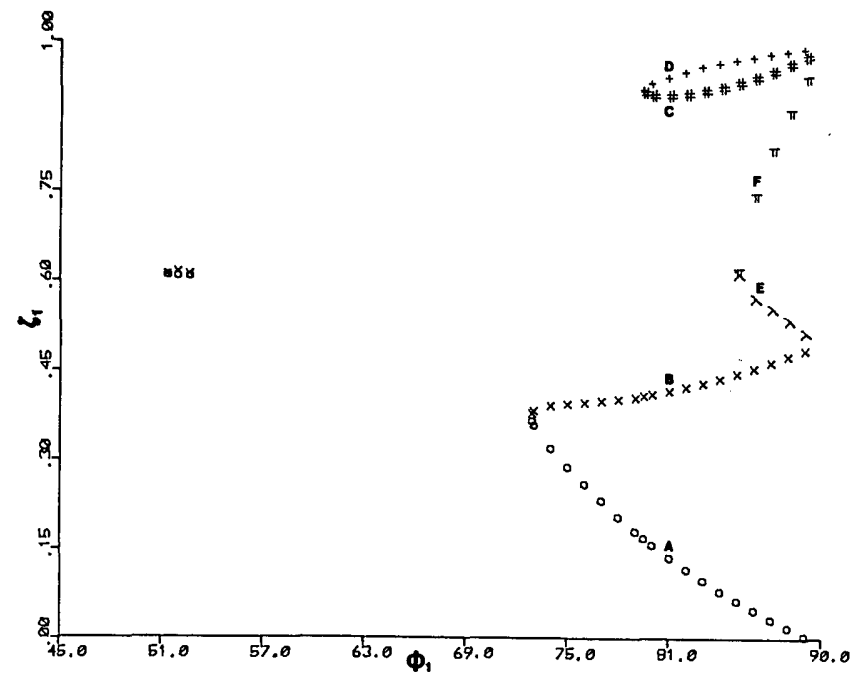

Fig. 12. Normalized film thickness $\zeta_{1}$ required for $Q W R\left(\left|\rho_{n}\right|=1\right.$, $\left.\Delta_{n}=-90^{\circ}\right)$ vs angle of incidence $\phi_{1}(\mathrm{deg})$ in a $\mathrm{ZnS}-\mathrm{Ag}$ three-reflection system at $\lambda=10.6 \mu \mathrm{m}$.

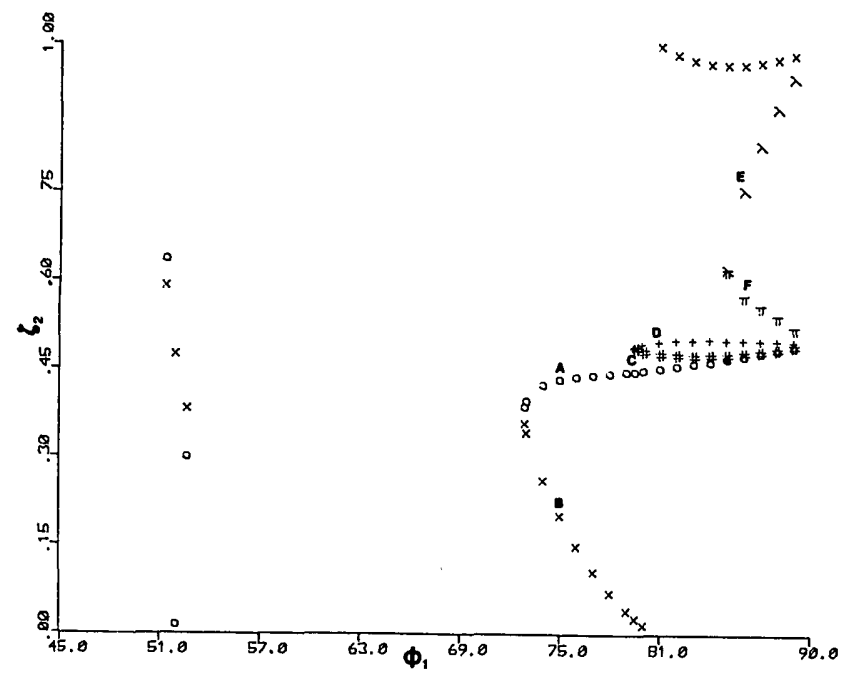

Fig. 13. Same as in Fig. 12 for the associated normalized film thickness $\zeta_{2}$.

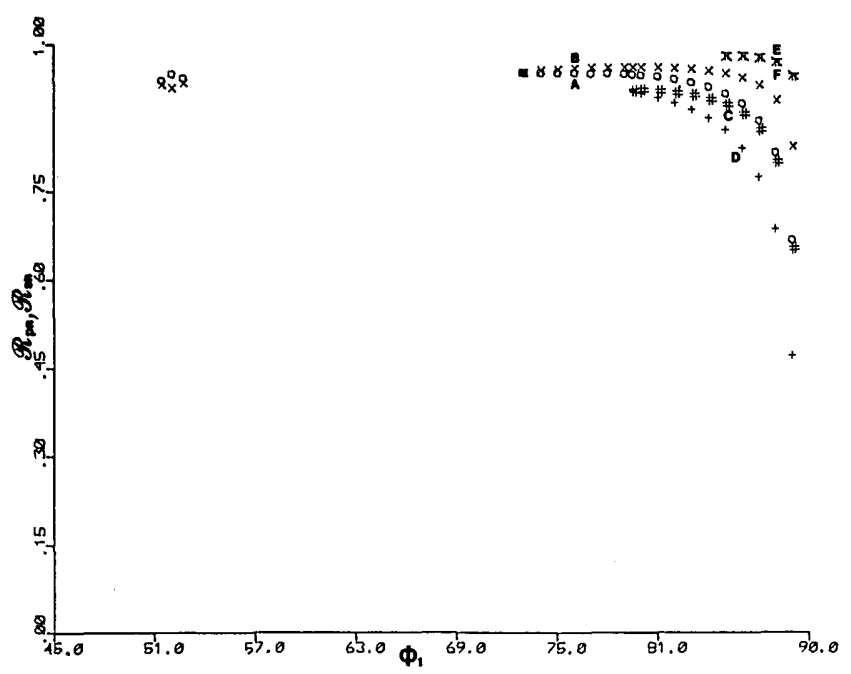

Fig. 14. Net intensity reflectances $\mathcal{R}_{p n}=\mathscr{R}_{s n}$ associated with the design solution pairs $\left(\zeta_{1}, \zeta_{2}\right)$ of Figs. 12 and 13.

Table VI. Magnitude and Phase Errors Caused by Introducing (I) FilmThickness Errors ( $\Delta d_{1}=\Delta d_{2}= \pm 1 \mathrm{~nm}$ ), (II) Angle-of-Incidence Errors $\left(\Delta \phi_{1}=\Delta \phi_{2}=\Delta \phi_{3}= \pm 0.5^{\circ}\right)$ to the QWR Designs of Table V

\begin{tabular}{|c|c|c|c|c|c|}
\hline \multirow{2}{*}{$\begin{array}{l}\text { Error } \\
\text { type }\end{array}$} & \multirow[b]{2}{*}{$\phi_{1}(\mathrm{deg})$} & \multicolumn{2}{|c|}{$\begin{array}{l}\text { Magnitude error } \\
\left(\left|\rho_{n}\right|-1\right) \times 10^{4}\end{array}$} & \multicolumn{2}{|c|}{$\begin{array}{c}\text { Phase error } \\
{\left[\Delta_{n}-\left(-90^{\circ}\right)\right](\mathrm{deg})}\end{array}$} \\
\hline & & - & + & - & + \\
\hline \multirow[t]{10}{*}{ I } & $52 A$ & 0.600 & -0.598 & -0.0537 & 0.0525 \\
\hline & $B$ & 0.536 & -0.534 & -0.0561 & 0.0550 \\
\hline & $75 A$ & -1.069 & 1.070 & -0.0802 & 0.0823 \\
\hline & $B$ & -1.086 & 1.097 & -0.0656 & 0.0677 \\
\hline & $85 A$ & -7.450 & 7.509 & -0.1615 & 0.1754 \\
\hline & $B$ & -2.898 & 2.965 & -0.0881 & 0.0940 \\
\hline & $C$ & -3.931 & 3.968 & -0.2024 & 0.2112 \\
\hline & $D$ & 5.385 & -5.588 & -0.3104 & 0.3006 \\
\hline & $E$ & 0.547 & -0.543 & -0.0339 & 0.0328 \\
\hline & $F$ & 0.547 & -0.543 & -0.0339 & 0.0329 \\
\hline \multirow[t]{10}{*}{ II } & $52 A$ & -0.087 & 0.087 & -2.0732 & 2.1074 \\
\hline & $B$ & -0.497 & 0.519 & -2.0382 & 2.0706 \\
\hline & $75 \mathrm{~A}$ & -2.882 & 3.002 & 5.1651 & -5.2389 \\
\hline & $B$ & 1.468 & -1.553 & 4.9799 & -5.0454 \\
\hline & $85 \mathrm{~A}$ & -4.030 & 7.251 & 14.0157 & -15.2209 \\
\hline & $B$ & 24.287 & -25.924 & 5.5888 & -5.5821 \\
\hline & $C$ & 0.643 & 2.541 & -8.0727 & 9.2161 \\
\hline & $D$ & 20.129 & -24.842 & -7.1972 & 8.5240 \\
\hline & $E$ & 0.034 & -0.044 & -6.6091 & 6.6386 \\
\hline & $F$ & -0.139 & 0.128 & -6.5987 & 6.6281 \\
\hline
\end{tabular}

Table V. Summary of Design Results for ZnS-Ag Three-Reflection Quarterwave Retarders with $s$ Fast Axis (QWR: $\left|\rho_{n}\right|=1, \Delta_{n}=\delta_{p n}-\delta_{s n}=-90^{\circ}$ ) at Three Angles of Incidence and at Wavelength $\lambda=10.6 \mu \mathrm{m}^{\text {a }}$

\begin{tabular}{rcccccrr}
\hline$\phi_{1}$ & $\zeta_{1}$ & $\zeta_{2}$ & $D_{\phi 1}$ & $D_{\phi 2}$ & $\mathcal{R}_{\nu n}$ & \multicolumn{1}{c}{$\delta_{p n}$} & \multicolumn{1}{c}{$\delta_{s n}$} \\
\hline $52 A$ & 0.60610 & 0.01252 & 2.5751 & 2.4238 & 0.9520 & -119.719 & -29.719 \\
$B$ & 0.61135 & 0.47032 & 2.5751 & 2.4238 & 0.9283 & 74.730 & 164.730 \\
$75 A$ & 0.28732 & 0.43199 & 2.6814 & 2.6207 & 0.9538 & -55.083 & 34.917 \\
$B$ & 0.39292 & 0.19710 & 2.6814 & 2.6207 & 0.9620 & -20.116 & 69.884 \\
$85 A$ & 0.06262 & 0.46531 & 2.7020 & 2.6941 & 0.9185 & -6.017 & 83.983 \\
$B$ & 0.44122 & 0.96412 & 2.7020 & 2.6941 & 0.9542 & 28.667 & 118.667 \\
$C$ & 0.93216 & 0.47129 & 2.7020 & 2.6941 & 0.9010 & -16.303 & 73.697 \\
$D$ & 0.96696 & 0.49627 & 2.7020 & 2.6941 & 0.8580 & -108.245 & -18.245 \\
$E$ & 0.61142 & 0.61570 & 2.7020 & 2.6941 & 0.9832 & 139.889 & -130.111 \\
$F$ & 0.61542 & 0.61130 & 2.7020 & 2.6941 & 0.9832 & 139.940 & -130.060 \\
\hline
\end{tabular}

a See footnote of Table I for explanation of notation. 


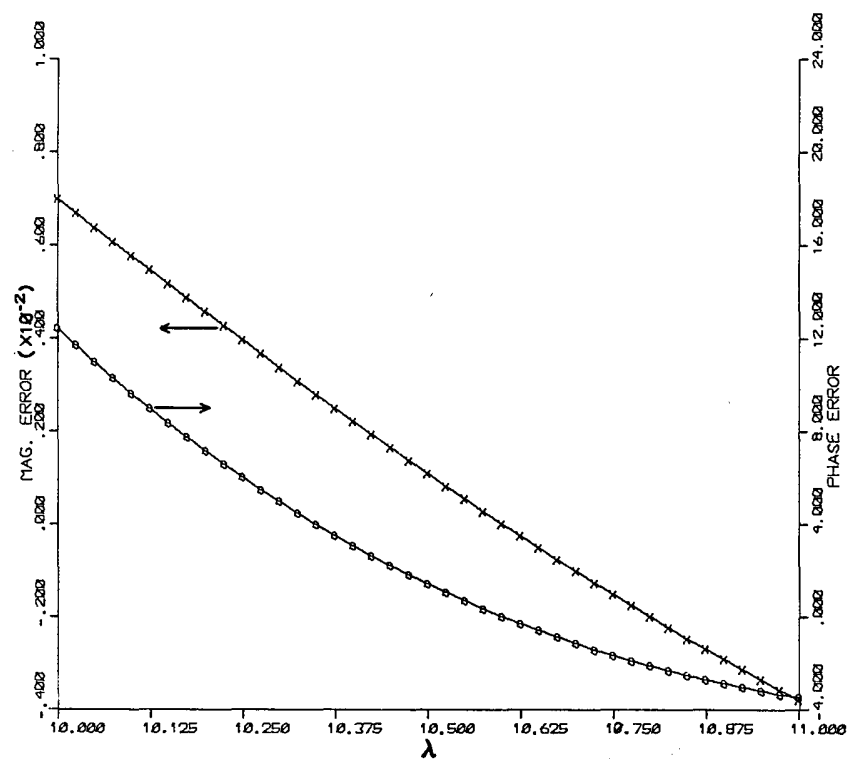

Fig. 15. Magnitude error $\left(\left|\rho_{n}\right|-1\right)$ and phase error $\left[\Delta_{n}-\left(-90^{\circ}\right)\right]$ caused by wavelength changes in the range $10 \mu \mathrm{m} \leq \lambda \leq 11 \mu \mathrm{m}$ for solution pair $A$ at $\phi_{1}=75^{\circ}$ of Table V.

This work was supported by a grant from the State of Louisiana Board of Regents and the Foundation for A Better Louisiana.

\section{Summary}

In this paper we have described in detail a procedure for the design of three-reflection (three-mirror) filmsubstrate systems with any desired ratio of net complex $p$ and $s$ reflection coefficients, hence any desired transformation of polarization. Examples are given of halfwave and quarterwave retarders that use $\mathrm{ZnS}$ coated $\mathrm{Ag}$ mirrors at the $\mathrm{CO}_{2}$-laser wavelength $\lambda=10.6$ $\mu \mathrm{m}$. The results appear graphically and in tables. The sensitivity to small film-thickness $( \pm 1-\mathrm{nm})$ and angleof-incidence $\left( \pm 0.5^{\circ}\right)$ errors is determined. Also specific designs have been tested for satisfactory operation over the wavelength range $10 \mu \mathrm{m} \leq \lambda \leq 11 \mu \mathrm{m}$.

\section{References}

1. R. M. A. Azzam and N. M. Bashara, Ellipsometry and Polarized Light (North-Holland, Amsterdam, 1977), p. 371.

2. R. M. A. Azzam, A. R. M. Zaghloul, and N. M. Bashara, "Ellipsometric Function of a Film-Substrate System: Applications to the Design of Reflection-Type Optical Devices and to Ellipsometry," J. Opt. Soc. Am. 65, 252 (1975).
3. A. R. M. Zaghloul, R. M. A. Azzam, and N. M. Bashara, "Design of Film-Substrate Single-Reflection Retarders," J. Opt. Soc. Am. 65, 1043 (1975).

4. A. R. M. Zaghloul, R. M. A. Azzam, and N. M. Bashara, "An Angle-of-Incidence Tunable, $\mathrm{SiO}_{2}-\mathrm{Si}$ (Film-Substrate) Reflection Retarder for the UV Mercury Line $\lambda=2537 \AA$," Opt. Commun. 14, 260 (1975).

5. A. R. M. Zaghloul, R. M. A. Azzam, and N. M. Bashara, " $\mathrm{SiO}_{2}-\mathrm{Si}$ Film-Substrate Reflection Retarders for Different Mercury Spectral Lines," Opt. Eng. 17, 180 (1978).

6. S. Kawabata and M. Suzuki, "MgF ${ }_{2}-\mathrm{Ag}$ Tunable Reflection Retarder," Appl. Opt. 19, 484 (1980).

7. R. M. A. Azzam and M. E. R. Khan, "Single-Reflection FilmSubstrate Halfwave Retarders with Nearly Stationary Reflection Properties over a Wide Range of Incidence Angles," J. Opt. Soc. Am. 73, 160 (1983).

8. W. H. Southwell, "Multilayer Coatings Producing $90^{\circ}$ Phase Change," Appl. Opt. 18, 1875 (1979).

9. J. H. Apfel, "Graphical Method to Design Multilayer Phase Retarders," Appl. Opt. 20, 1024 (1981).

10. J. H. Apfel, "Phase Retardance of Periodic Multilayer Mirrors," Appl. Opt. 21, 733 (1982).

11. R. M. A. Azzam and N. M. Bashara, Ellipsometry and Polarized Light (North-Holland, Amsterdam, 1977), Sec. 4.3.

12. R. M. A. Azzam and M. E. R. Khan, "Polarization-Preserving Single-Layer-Coated Beam Displacers and Axicons," Appl. Opt. 21, 3314 (1982).

13. G. W. Stagg and A. H. El-Abiad, Computer Methods in Power System Analysis (McGraw-Hill, New York, 1968), p. 249. 